\title{
Omega-3 fatty acid supplementation and cognitive function: are smaller dosages more beneficial?
}

This article was published in the following Dove Press journal:

International Journal of General Medicine

19 September 2014

Number of times this article has been viewed

\author{
Abdul-Razak Abubakari' \\ Mohammad-Mahdi \\ Naderali ${ }^{2}$ \\ Ebrahim K Naderali ${ }^{3}$ \\ 'School of Health and Life Sciences, \\ Glasgow Caledonian University, \\ London, UK; ${ }^{2}$ Blue Coat School, \\ Liverpool, UK; ${ }^{3}$ School of Health \\ Sciences, Liverpool Hope University, \\ Hope Park Campus, Liverpool, UK
}

\begin{abstract}
As longevity increases, so does the global prevalence of cognitive dysfunction. Numerous lifestyle and/or dietary interventions such as omega-3 fatty acids have been suggested to improve memory. Therefore, this study examined the consistency and strength of the impact of supplementation of omega-3 fatty acids on overall cognitive function using systematic reviews and meta-analytic methods. Of 905 studies retrieved from all searches, 12 randomized controlled trials were included in the meta-analysis. There were differences between studies reporting outcomes for single memory function parameters. Subgroup analysis of doses used (low versus high) indicated that subjects receiving low $(<1.73 \mathrm{~g} /$ day) doses of omega-3 fatty acids had a significant reduction in cognitive decline rate $(-0.07,95 \%$ confidence interval $-0.01,-0.02)$ but there was no evidence for beneficial effects at higher doses $(+0.04$, $95 \%$ confidence interval $-0.06,+0.14$ ) compared with the placebo group. This study suggests that omega-3 fatty acids may be beneficial in preventing memory decline at lower doses.
\end{abstract}

Keywords: cognitive impairment, Alzheimer's disease, dietary fatty acids, omega-3, docosahexaenoic acid

\section{Introduction}

The prevalence of dementia is increasing with increased life expectancy and longevity, and is estimated to reach over 34 million worldwide by $2025 .{ }^{1,2}$ In the UK, there are over 800,000 people living with dementia, of whom approximately 17,000 are under the age of 65 years, and it is estimated to increase to nearly one million by 2021 and approximately 1.7 million by $2051 .^{2,3}$

Although a number of hypotheses have been put forward to explain the etiology of cognitive decline, the exact etiology of dementia is not fully understood and it is not clear what can be done to prevent memory loss. ${ }^{4-6}$ Nonetheless, the evidence indicates that a healthy diet and lifestyle may help to protect against dementia. There are a number of human studies reporting clear associations between lifestyle and late-life cognitive decline. In particular, exercising regularly, avoiding fatty foods, not smoking, drinking alcohol in moderation, and keeping mentally and socially active into old age may help to reduce the risk of developing vascular dementia and Alzheimer's disease.?

The role of healthy diet has been well established in a number of chronic illnesses, including obesity, diabetes, cardiovascular disease, and several cancers. Interestingly, nutrition has also been linked to delaying the onset of Alzheimer's disease or slowing its progression. ${ }^{8-10}$ Amongst various nutritional elements, polyunsaturated fatty acids such as omega-3 are considered to exert positive effects on cognitive function. However, the outcome of published reports varies considerably between the studies
Correspondence: Ebrahim K Naderal School of Health Sciences, Liverpool Hope University, Hope Park,

Liverpool, LI6 9JD, UK

Tel +44 I5I 29I 3439

Fax +44 I5I 29I 34I 4

Email naderae@hope.ac.uk
International Journal of General Medicine 20I4:7 463-473 (c) (i) (5) 2014 Abubakari et al. This work is published by Dove Medical Press Limited, and licensed under Creative Commons Attribution - Non Commercial (unported, v3.0) permission from Dove Medical Press Limited, provided the work is properly attributed. Permissions beyond the scope of the License are administered by Dove Medical Press Limited. Information on permission from Dove Medical Press Limited, provided the work is properly attributed. P
how to request permission may be found at: http://www.dovepress.com/permissions.php 
depending on the cognitive parameters assessed, the study period, the selected population, and the omega-3 doses used. Apart from variations in sample and contextual characteristics, inconsistencies in the effect of interventions may also arise as a result of other factors, including lack of sufficient power (inadequate sample size) to detect a difference, especially where the effect of the intervention under consideration is small. Some of these problems (eg, variations in participant characteristics and inadequate sample size) can be addressed in part by carefully bringing together all existing evidence on the intervention, critically examining the assembled studies based on quality and comparability, and where appropriate, pooling the results of methodologically similar studies by statistical synthesis. Thus, this study examined the impact of omega-3 supplementation on composite cognitive function using systematic reviews and meta-analytic procedures.

\section{Materials and methods}

\section{Search criteria}

Electronic searches were conducted in PubMed, Web of Science (which included Medline and PsycINFO), and the Cochrane database of registered controlled trials. Reference lists of included articles were also searched. Appropriate search terms (key word and Medical Subject Headings) were used, and retrieved searches were combined using relevant Boolean operators (OR, AND). Where appropriate, search terms were truncated using relevant wild cards to retrieve alternative forms of the search terms, thereby increasing sensitivity. Search terms used included: "omega-3 fatty acid", "polyunsaturated fatty acid", "dietary fatty acid", "alpha linolenic acid" (ALA), "linolenic acid", "eicosapentaenoic acid" (EPA), "docosapentaenoic acid” (DPA), “docosahexaenoic acid" (DHA), "fish oil”, "essential fatty acid", "cognitive function", "cognitive dysfunction", “cognitive impairment", "dementia", "Alzheimer's disease", "memory function", "memory impairment", "memory loss", "cognitive decline", and "cognitive performance".

Titles and abstracts of studies retrieved from searches were considered for inclusion independently by two reviewers. Full texts of articles that seemed to meet the inclusion criteria were obtained for further scrutiny. Also, full texts of articles which could not be excluded with certainty based on the title and the abstract were obtained and scrutinized further for inclusion or otherwise. Differences in opinion between the two reviewers were resolved by consensus. Electronic searches and study selection were conducted from June 2011 to September 2011.

\section{Inclusion/exclusion criteria}

We considered studies that reported the consumption or supplementation of any omega-3 fatty acids (ALA, EPA, DHA, DPA) or fish (or fish oil) and their relationship with cognitive function/decline. Studies included were randomized controlled trials (RCTs) reporting data on either healthy or clinical populations. Studies comparing omega-3 fatty acids versus control or placebo and reporting a measure of cognitive endpoints were included.

All forms of omega-3 fatty acid interventions were considered. Thus, interventions involving more than one component were included if the results for the omega- 3 fatty acid component could be isolated. Interventions evaluating the effect of a single component of omega-3 fatty acid (eg, DHA, DPA, EPA, or ALA), combined omega-3 fatty acids (eg, DHA and EPA), or fish oil on cognitive function were also included. However, studies reporting omega-3 fatty acids or fish consumption plus another active compound where data for omega-3 fatty acids or fish intake could not be isolated from the other active compound were not included. Also, studies reporting any reasonable length of follow-up, dosage of supplementation, or type of sample population (healthy or clinical) were included.

The main outcome of interest was the mean change in global memory or cognitive function determined by an appropriate measure or scale, such as the Mini-Mental State Examination (MMSE). Where results for global cognitive function were not apparent, an appropriate specific scale of cognitive function (eg, word recall, verbal fluency) was used. No secondary outcomes were considered. Studies that did not report any measure of cognitive function were excluded. Also, studies that did not report sufficient data to permit the computation of effect size (mean difference) were not included. There was no restriction on age of participants.

\section{Data extraction and quality assessment}

A data extraction form was used to collect relevant information from individual studies. Information collected from studies included study methods and participant characteristics (eg, setting, population from which the sample was recruited, mean age), intervention/control characteristics, and study quality indicators such as randomization, blinding, treatment concealment, and dropouts (see Table 1). As shown in Table 2, relevant data on the outcome measures of interest (mean of cognitive outcome at baseline, mean of cognitive outcome at follow-up, and if reported, mean changes from baseline to follow-up and their respective standard deviations) were also 
extracted. Although data on methodological quality indicators (eg, blinding, randomization, withdrawal/loss to follow-up) were extracted and are reported here, we did not actively rate the quality of studies included in this review.

\section{Statistical analysis}

In most of the studies, changes in cognitive function from baseline were not reported. These values were therefore computed from the relevant data (number of participants, mean, and standard deviation) reported at baseline and at follow-up. This is a conservative approach as it overestimates the standard deviation for the respective studies. As shown in Table 1, the studies used different scales/instruments to measure cognitive function/decline. Thus, the standardized mean difference (SMD) was used to compute the pooled treatment effect comparing intervention and control groups. The SMD is expressed as the absolute difference in means of the intervention and control groups divided by the pooled standard deviation.

For subanalysis of examining effects of dose differences, median dose of supplementation $(1.7 \mathrm{~g} /$ day $)$ was computed and used to divide studies into two groups of low-dose $(\leq 1.7 \mathrm{~g} /$ day $)$ or high-dose $(>1.7 \mathrm{~g} /$ day $)$.

Meta-analyses were conducted using the fixed effects model, as there was no evidence of heterogeneity in any of the pooled analyses conducted to justify the use of a random effects model. Pooled estimates were conducted for all studies combined as well as for study subgroups based on treatment dose ( $\leq$ median dose/ $>$ median dose), duration of intervention (short-term $<6$ months/longterm $\geq 6$ months), and types of study participants (healthy/ clinical population). The data were analyzed using the metan command in Stata version 9 (StataCorp LP, College Station, TX, USA).

\section{Results}

\section{Description of included studies}

As shown in Figure 1, 905 studies were retrieved from all the searches conducted and 12 RCTs were included in the meta-analysis. Table 1 shows details of the methodological and participant characteristics of the studies included in this review. Over half of the studies $(n=7)$ were conducted in general or healthy populations. ${ }^{11-16}$ The others were conducted in specific clinical or special populations including people with: schizophrenia, ${ }^{17}$ various degrees of memory problems, ${ }^{18-20}$ depression, ${ }^{21}$ or pregnant women..$^{22}$ Included studies varied in sample size, ranging from 53 subjects $^{11}$ to 867 subjects. ${ }^{16}$ Freund-Levi et al ${ }^{19}$ used a randomized, double-blind, parallel-group study design for the first 6 months and then open treatment for all participants thereafter. All other studies were double-blind, parallel-group RCTs. Five of the studies involved young adult/middle-aged samples (mean age $\leq 40$ years), ${ }^{11,14,17,21,22}$ and all other studies involved older population samples (mean age $\geq 68$ years).

Interventions were mostly presented as supplements in capsules as combinations of DHA and EPA, ${ }^{12,16,19-21}$ DHA only, ${ }^{11,13,15,18}$ EPA only, ${ }^{18}$ ALA (the dietary precursor of DHA) ${ }^{22}$ or fish oil. ${ }^{14}$ Duration of intervention and follow-up ranged from 4 weeks to 24 months (median 23 weeks) and daily consumed doses of a single or combined components of omega-3 fatty acids ranged from $0.58 \mathrm{~g}$ of combined DHA and EPA ${ }^{19}$ to $3.12 \mathrm{~g}$ of ALA. ${ }^{22}$ Loss to follow-up was reported in ten of the included studies, and ranged from $3 \%{ }^{12}$ to $27 \%{ }^{18}$

\section{Effect of omega-3 fatty acids on cognitive function/decline}

Considering the results for individual studies included in this review, only Yurko-Mauro et $\mathrm{al}^{15}$ reported significant changes in measures of cognitive function/decline for all participants randomized to omega-3 fatty acid intervention compared with placebo. Specifically, they found that participants randomized to DHA scored significantly fewer errors in the $\mathrm{Cantab}^{\circledR}$ paired associate learning (PAL) measure compared with those randomized to placebo (mean difference $-1.63 \pm 0.76 ; P=0.032$ ) after 24 weeks of supplementation. They also reported significant differences in other subscales of the Cantab measure but not MMSE scores between the intervention and placebo groups.

Some studies reported a significant effect of omega-3 fatty acid supplementation only after detailed investigations were conducted within subgroups of study participants. For example, compared with their omega- 3 fatty acid intervention group, Freund-Levi et $\mathrm{al}^{19}$ reported a significant decrease in MMSE scores $(P=0.01)$ for their control group when subgroup analysis was conducted for participants with very mild Alzheimer's disease (MMSE > 27 and Clinical Dementia Rating score 0.5-1). The change in MMSE scores for the omega-3 fatty acid group after 6 months of supplementation was -0.5 points $(P>0.05)$ compared with -2.6 points $(P<0.001)$ in the placebo group. Also, the placebo group experienced a significant worsening in cognitive function (as indicated by scores on the "delayed word recall" subscale of the Alzheimer's Disease Assessment Scale-Cognitive Subscale [ADAS-cog]; $P=0.007$ ) compared with no change in the intervention group. Chiu et $\mathrm{al}^{20}$ also reported improvement 


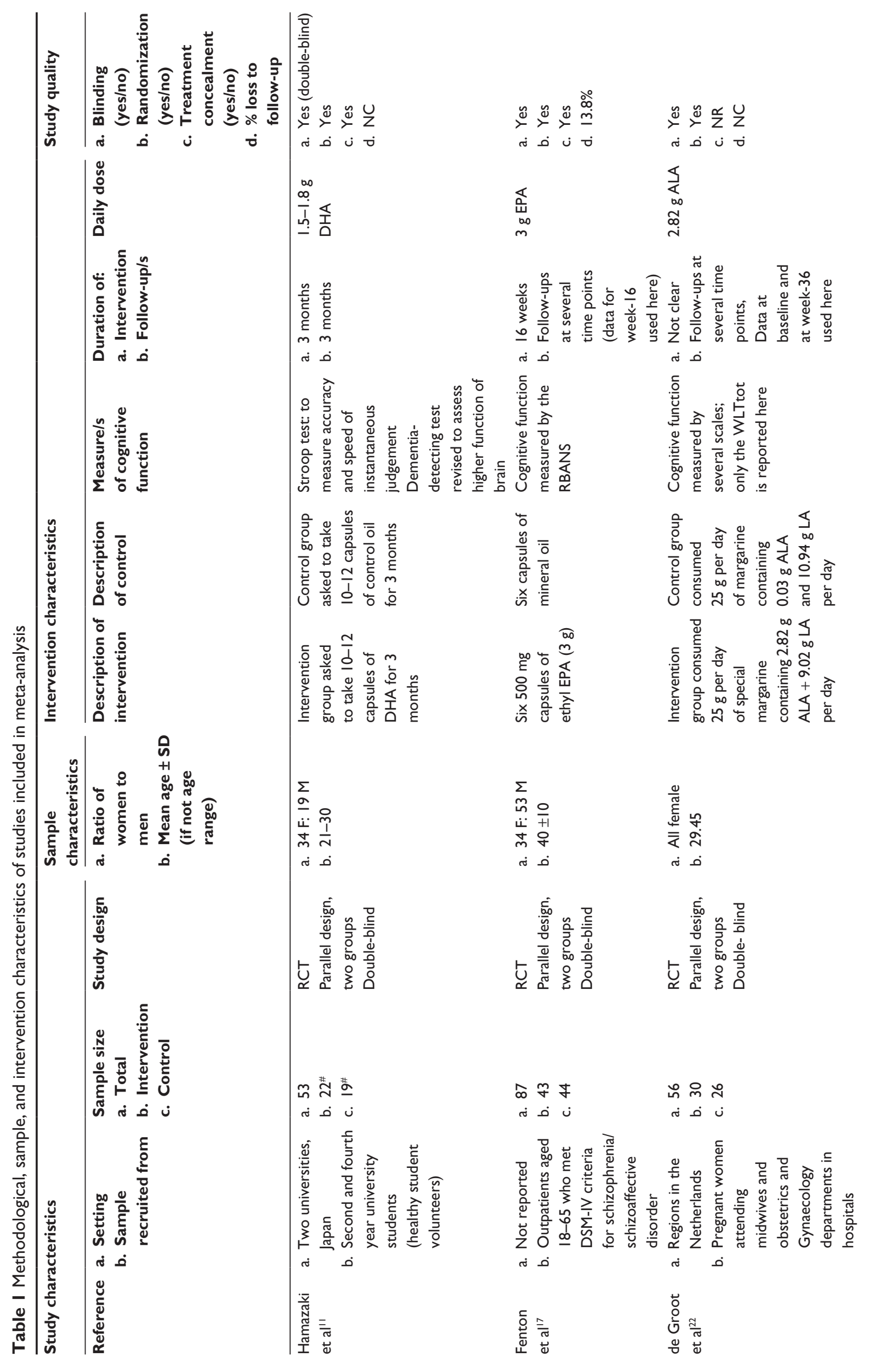




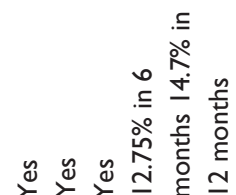

نं ن ن

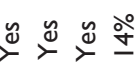

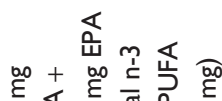

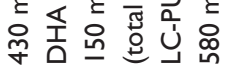

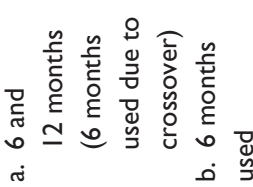

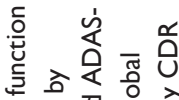

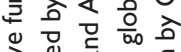

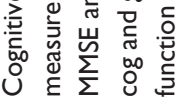

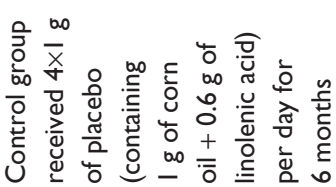

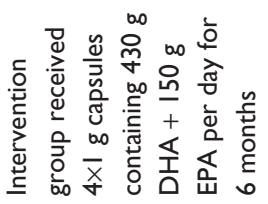

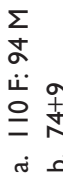

तं ن

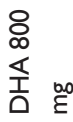

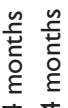

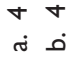

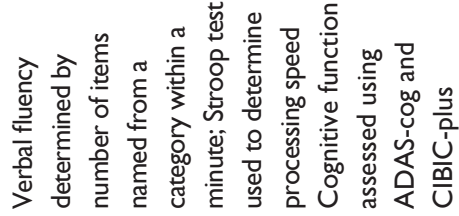

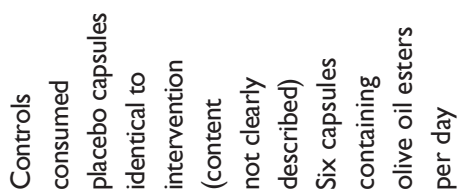

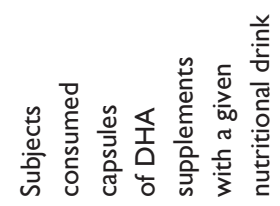

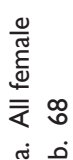

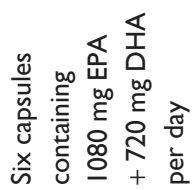

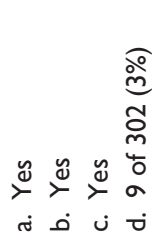

¿ั

인존

唄这

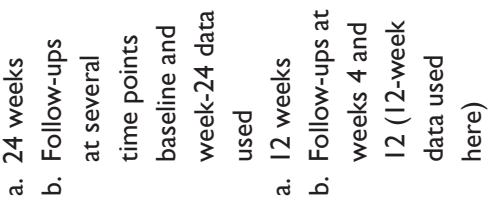

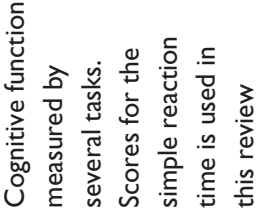

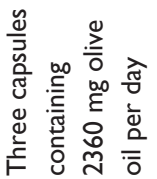

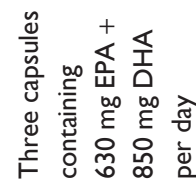

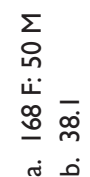

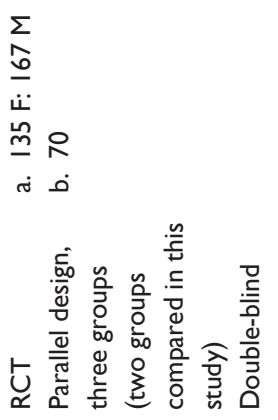

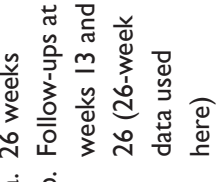

त

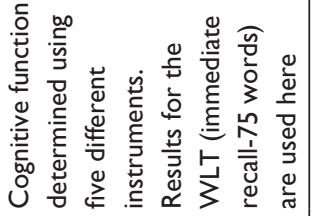

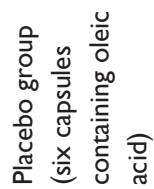

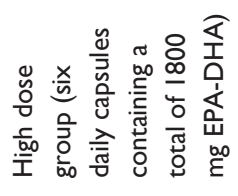

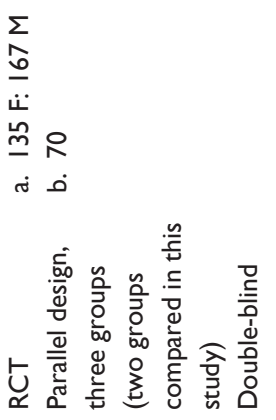

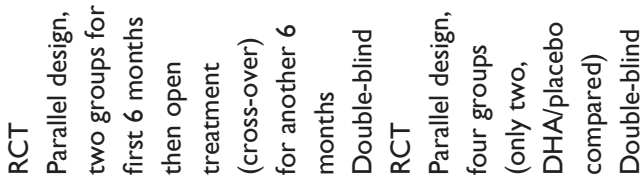

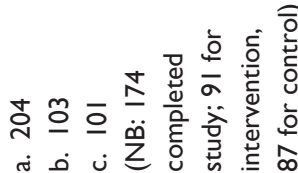

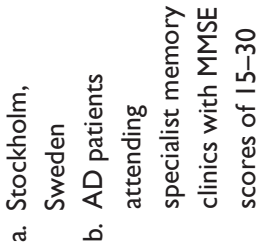

㞱离
的娄拦

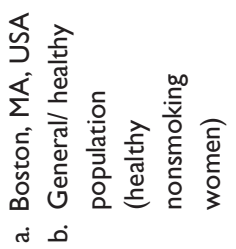

드을 $d \stackrel{4}{d}$

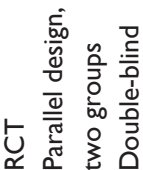

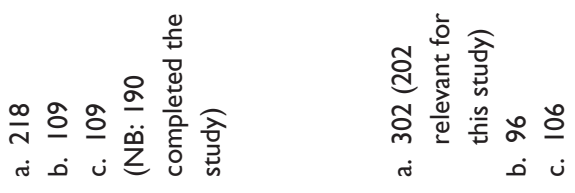

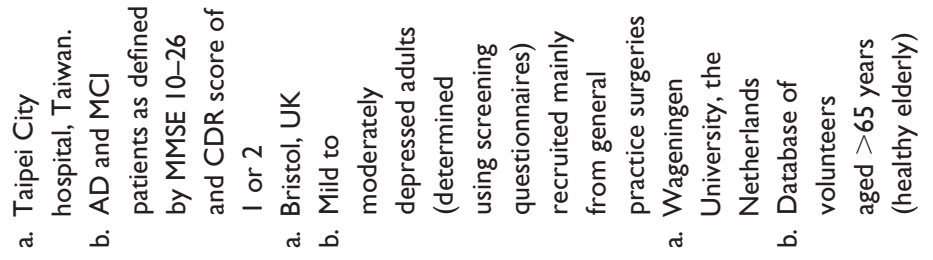

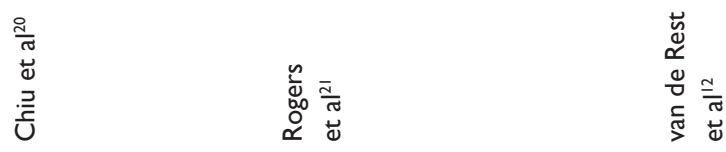




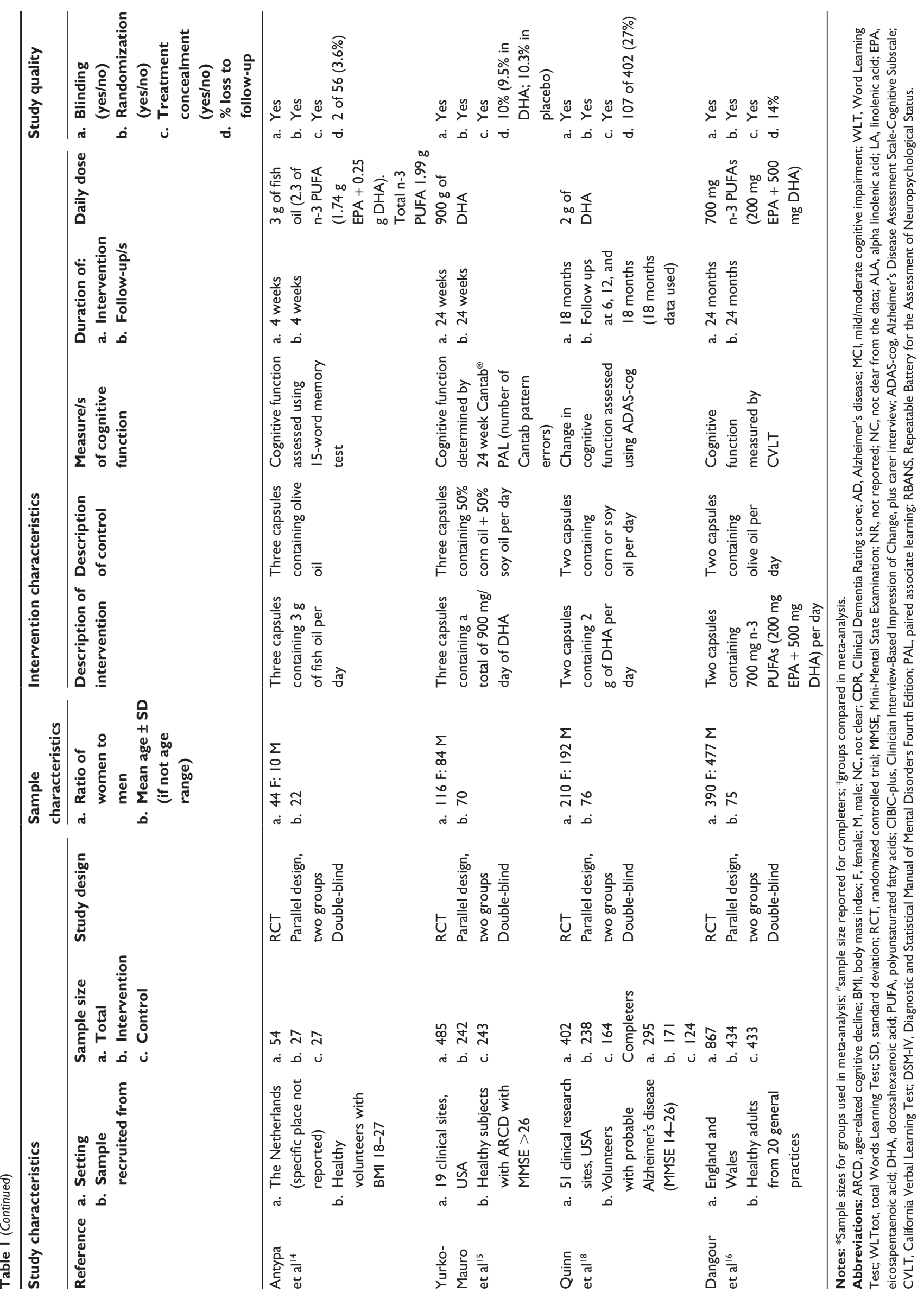


Table 2 Data analysis strategy, measures of cognitive function, and results from included studies

\begin{tabular}{|c|c|c|c|c|c|}
\hline $\begin{array}{l}\text { Study } \\
\text { reference }\end{array}$ & $\begin{array}{l}\text { Analysis strategy } \\
\text { (ITT/PP) }\end{array}$ & $\begin{array}{l}\text { Measures of cognitive } \\
\text { function used in current study }\end{array}$ & $\begin{array}{l}\text { Indicator of cognitive } \\
\text { improvement }(\uparrow \downarrow)\end{array}$ & $\begin{array}{l}\text { Outcome of interest } \\
\text { (intervention group) }\end{array}$ & $\begin{array}{l}\text { Outcome of interest } \\
\text { (control group) }\end{array}$ \\
\hline Hamazaki & PP & Stroop test $(100 \%)$ & $\uparrow(+)$ & BL, $50.8 \pm \mathrm{I} I .4$ & BL, $51.1 \pm 12.7$ \\
\hline \multirow[t]{3}{*}{ et $\mathrm{al}^{\prime \prime}$} & & & & Final, $57.4 \pm 15.2$ & Final, $59.3 \pm 14.6$ \\
\hline & & Dementia-detecting test (DDT) & $\downarrow(-)$ & BL, $46.6 \pm 8.0$ & BL, $49.1 \pm 9.9$ \\
\hline & & $(100 \%)$ & & Final, $55.5 \pm 9.1$ & Final, $57.9 \pm 8.7$ \\
\hline Fenton & ITT & RBANS & $\uparrow(+)$ & BL, $75 \pm 15$ & BL, $77 \pm 40$ \\
\hline et $\mathrm{al}^{17}$ & & & & Final, $76 \pm 18$ & Final, $74 \pm 14$ \\
\hline de Groot & NC & (WLTtot) & $\uparrow(+)$ & BL, $9.9 \pm 1.3$ & $B L, 10.5 \pm 1.8$ \\
\hline et $\mathrm{al}^{22}$ & & & & Final, $10.9 \pm 1.5$ & Final, II.4 \pm 1.4 \\
\hline \multirow{6}{*}{$\begin{array}{l}\text { Freund-Levi } \\
\text { et al }{ }^{19}\end{array}$} & ITT/PP but results & MMSE (0-30 points) & $\uparrow(+)$ & BL, $23.6(22.8-24.4)$ & BL, $23.2(22.4-24.0)$ \\
\hline & reported in PP & & & Final, $22.8(21.9-23.7)$ & Final, 22.4 (21.5-23.4) \\
\hline & & ADAS-cog (0-85 points) & $\downarrow(-)$ & BL, 25.7 (23.6-27.8) & BL, $27.2(25.1-29.4)$ \\
\hline & & & & Final, $27.7(25.4-30.0)$ & Final, $28.3(26.0-30.6)$ \\
\hline & & CDR global score & $\downarrow(-)$ & BL, I.0 (0.9-I.I) & BL, I.I (I.0-I.2) \\
\hline & & (0-3 points) & & Final, I.I (I.0-I.2) & Final, I.I (I.0-I.3) \\
\hline \multirow{4}{*}{$\begin{array}{l}\text { Johnson } \\
\text { et } \mathrm{al}^{13}\end{array}$} & PP & Verbal fluency & $\uparrow(+)$ & BL, $15.0 \pm 4.9$ & $B L, 12.9 \pm 6.2$ \\
\hline & & & & Final, $\mid 7.8 \pm 3 . I^{*}$ & Final, $13.8 \pm 3.5$ \\
\hline & & Stroop test (total RT- & $\uparrow(+)$ & BL, $21.5 \pm 10.0$ & BL, $25.0 \pm 14.8$ \\
\hline & & interference) & & Final, $19.7 \pm 8.3$ & Final, $23.1 \pm 22.0$ \\
\hline \multirow[t]{4}{*}{ Chiu et $\mathrm{a}^{20}$} & ITT/PP & ADAS-cog & $\downarrow(-)$ & BL, $9.17 \pm 7.19$ & BL, $7.99 \pm 7.13^{*}$ \\
\hline & & & & Final, $5.90 \pm 5.63$ & Final, $5.57 \pm 4.76$ \\
\hline & & MMSE & $\uparrow(+)$ & BL, $25.06 \pm 3.99$ & BL, $25.27 \pm 3.34$ \\
\hline & & & & Final, $25.47 \pm 3.8 \mathrm{I}$ & Final, $25.09 \pm 3.67$ \\
\hline Rogers & ITT/PP & Cognitive function measured using & $\downarrow(-)$ & BL, $370 \pm 75$ & $\mathrm{BL}, 38 \mathrm{I} \pm 56$ \\
\hline et $\mathrm{al}^{21}$ & PP used for cognitive & various tasks. Scores for simple & & Final, $391 \pm 85$ & Final, $398 \pm 7 \mid$ \\
\hline & function tests & reaction time is used & & & \\
\hline van de Rest & ITT & WLT (immediate recall-75 & $\uparrow(+)$ & BL, $39.3 \pm 8.8$ & BL, $39.6 \pm 9.7$ \\
\hline et $\mathrm{al}^{12}$ & & words) & & Final, $44.9 \pm 9.9$ & Final, $44.8 \pm 9.4$ \\
\hline Antypa & PP & I5-word list memory test: & $\uparrow(+)$ & BL, $9.55 \pm 2.48$ & BL, $9.04 \pm 2.54$ \\
\hline \multirow[t]{3}{*}{ et $\mathrm{a}^{1 / 4}$} & & Delayed recall & & Final, 9.36 \pm 3.24 & Final, $9.92 \pm 3.22$ \\
\hline & & Immediate recall & $\uparrow(+)$ & BL, I I.04 \pm 2.66 & BL, $10.72 \pm 2.56$ \\
\hline & & & & Final, I I.0 $0 \pm 2.83$ & Final, II.04 $\pm 2.6 \mathrm{I}$ \\
\hline Yurko- & ITT & Cantab $^{\circledR}$ PAL & $\downarrow(-)$ & BL, $|3.4 \pm 1| .6$ & $B L, 12.1 \pm 10.9$ \\
\hline Mauro & & & & Final, $8.8 \pm 9.9$ & Final, $9.7 \pm 10.7$ \\
\hline \multirow[t]{2}{*}{ et $\mathrm{al}^{15}$} & & MMSE & $\uparrow(+)$ & BL, $28.3 \pm 1.3$ & BL, $28.2 \pm 1.3$ \\
\hline & & & & Final, $28.0 \pm 1.9$ & Final, $27.9 \pm 1.9$ \\
\hline Quinn & ITT & ADAS-cog & $\downarrow(-)$ & Mean change $(95 \% \mathrm{Cl})$ & Mean change $(95 \% \mathrm{Cl})$ \\
\hline \multirow[t]{3}{*}{ et $\mathrm{al}^{18}$} & PP used in & CDR, sum of boxes & $\downarrow(-)$ & $7.98(6.5 \mathrm{I}-9.45)$ & $8.27(6.72-9.82)$ \\
\hline & secondary analysis & & & $2.87(2.44-3.30)$ & $2.93(2.44-3.42)$ \\
\hline & & MMSE & $\uparrow(+)$ & $-3.70(-4.44,-2.96)$ & $-4.04(-4.85,-3.23)$ \\
\hline \multirow{8}{*}{$\begin{array}{l}\text { Dangour } \\
\text { et } \text { al }^{16}\end{array}$} & ITT & CVLT-total words recalled & $\uparrow(+)$ & BL, $24 . I \pm 6.0$ & BL, $23.9 \pm 5.7$ \\
\hline & & & & Final, $24.1 \pm 6.7$ & Final, $24.4 \pm 6.4$ \\
\hline & & Immediate story recall & $\uparrow(+)$ & BL, $11.1 \pm 3.9$ & BL, $10.7 \pm 3.9$ \\
\hline & & & & Final, $11.0 \pm 4.3$ & Final, $10.9 \pm 3.9$ \\
\hline & & Delayed story recall & $\uparrow(+)$ & $\mathrm{BL}, 8.9 \pm 3.8$ & BL, $8.8 \pm 3.7$ \\
\hline & & & & Final, $9.3 \pm 4.2$ & Final, $9.1 \pm 3.8$ \\
\hline & & Verbal fluency & $\uparrow(+)$ & BL, $19.8 \pm 5.1$ & BL, $19.9 \pm 5.0$ \\
\hline & & & & Final, $19.1 \pm 5.4$ & Final, $19.5 \pm 5.3$ \\
\hline
\end{tabular}

Notes: - This study used a cross-over design, thus results for first 6 months are compared; $* p<0.05$. The upward arrows and (+) indicate cognitive improvement in cognitive outcome in intervention group compared to the control group. Similarly, downward arrow and $(-)$ indicate decline in cognitive outcome in intervention group compared to control group.

Abbreviations: BL, baseline; CVLT, California Verbal Learning Test; ITT, intention-to-treat analysis; NC, not clear from data; PP, per protocol analysis; CDR, Clinical Dementia Rating score; WLT, Word Learning Test; WLTtot, total Words Learning Test; MMSE, Mini-Mental State Examination: ADAS-cog, Alzheimer's Disease Assessment Scale-Cognitive Subscale; RBANS, Repeatable Battery for the Assessment of Neuropsychological Status; CI, confidence interval; PAL, paired associate learning; RT, total interference from Stroop test for speed and accuracy of processing.

in cognitive function (indicated by reduced scores on ADAS-cog) in participants with mild cognitive impairment supplemented with omega-3 fatty acids compared with placebo $(-3.23 \pm 3.82$ versus $-0.37 \pm 1.4 ; P=0.03)$. The study by van de Rest et a ${ }^{12}$ also reported significant improvement in the cognitive domain of attention among apolipoprotein 


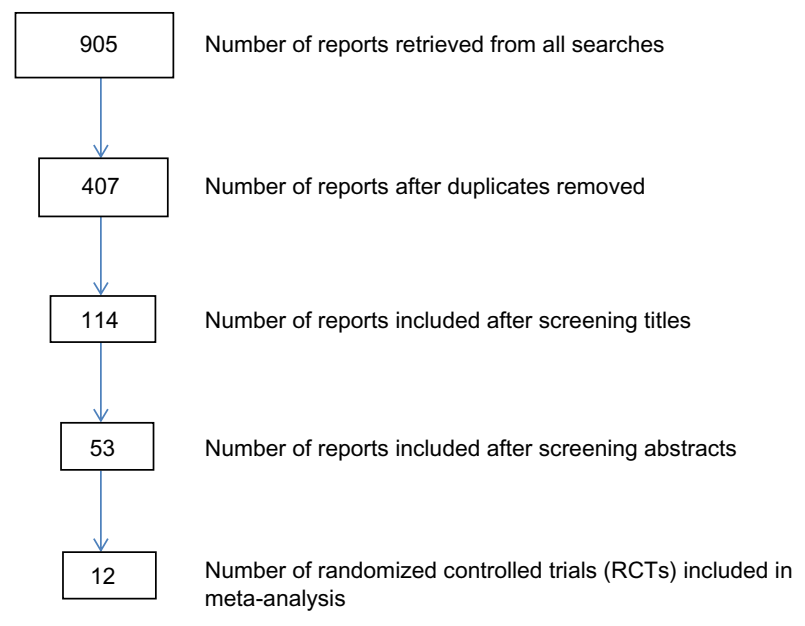

Figure I Search results and number of studies included at various stages.

E $\varepsilon 4$ carriers and men supplemented with fish oil compared with controls. Another study ${ }^{13}$ reported significant withingroup change in cognitive function in the intervention group but not in the control group. Compared with baseline scores, participants in the intervention (DHA) group named significantly more items (2.8) from a category within a minute after 4 months of supplementation. However, there was no improvement in the number of items ( 0.9$)$ named by participants in the control group within the same period.
Pooled analysis involved 2,510 participants, with 1,298 and 1,212 randomized to the intervention and control groups, respectively. The median duration of intervention was 23 (range 4-96) weeks. As shown in Figure 2, results for all the studies combined were consistent with the individual findings from most studies. The pooled results showed no significant change in memory function following supplementation with omega-3 fatty acids or the component elements (pooled SMD $-0.04,95 \%$ confidence interval $[\mathrm{CI}]-0.09,+0.01)$. As shown in the forest plot of the meta-analysis, only one study (Yurko-Mauro et al ${ }^{15}$ ) showed significant improvement in cognitive function (based on the Cantab PAL measure) following omega-3 fatty acid supplementation (SMD -0.21 ; $95 \% \mathrm{CI}-0.3,-0.04)$. Heterogeneity between studies was not statistically significant $\left(\chi^{2}=11.99, d f=23, P=0.97\right)$.

There were no significant differences in cognitive function between the intervention and control groups when pooled analyses were stratified by duration of follow-up ([short-term $<6$ months SMD $-0.08,95 \%$ CI $-0.16,+0.01]$; [long-term $\geq 6$ months SMD $-0.03,95 \%$ CI $-0.09,+0.03])$; type of participants included ([general/healthy population SMD $-0.04,95 \% \mathrm{CI}-0.10,+0.01]$; [diseased/clinical population SMD 0.00, 95\% CI -0.10, +0.09]). However, there was a statistically significant effect when analysis was stratified by

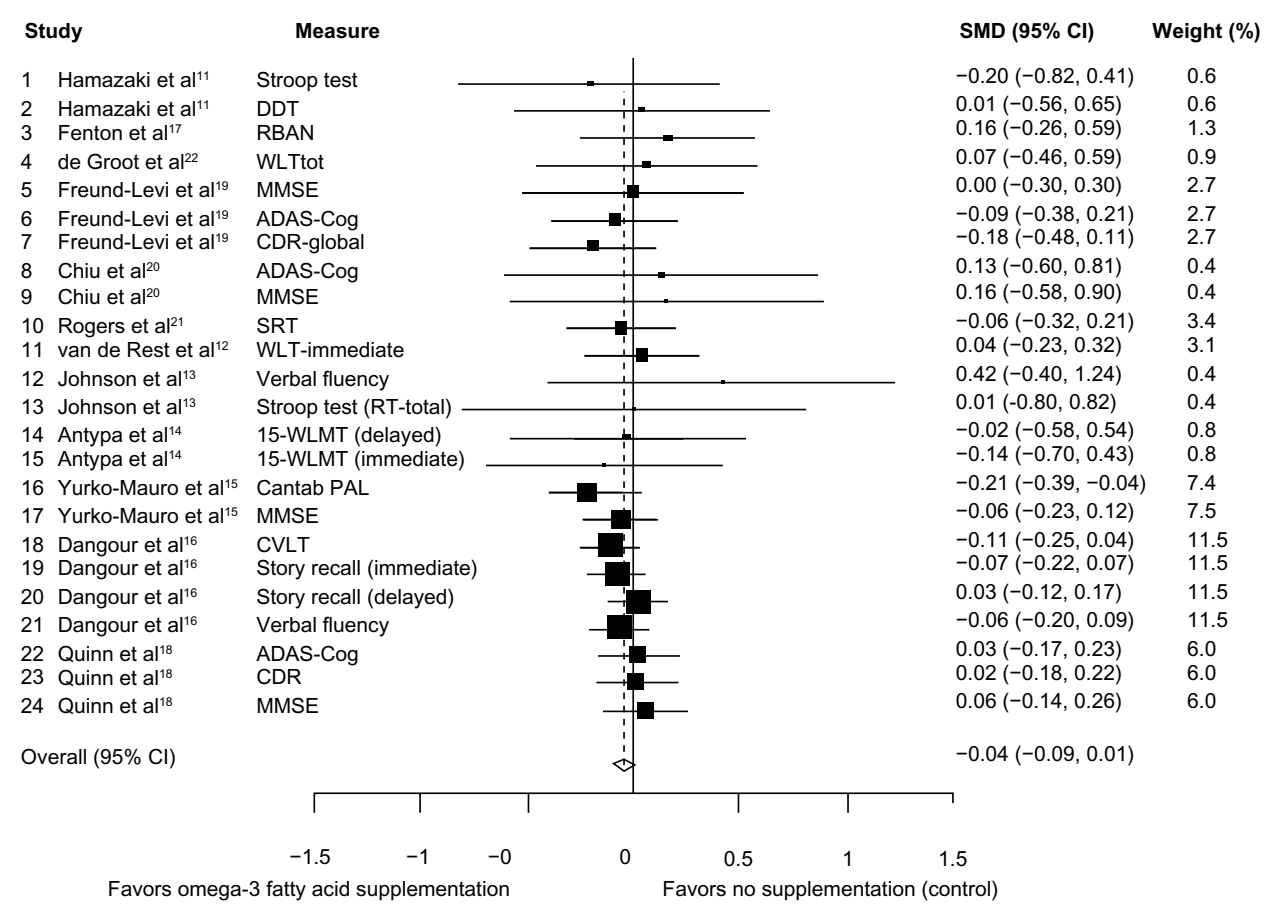

Figure 2 Forest plot for omega-3 fatty acid supplementation and cognitive decline.

Abbreviations: ADAS-cog, Alzheimer's Disease Assessment Scale-Cognitive Subscale; Cl, confidence interval; CVLT, California Verbal Learning Test; DDT, dementia detecting test; WLTtot, total Words Learning Test; I5-WLMT, Word List (memory) Test; RBANS, Repeatable Battery for the Assessment of Neuropsychological Status; MMSE, Mini-Mental State Examination; WLT, Word Learning Test; PAL, paired associate learning; CDR, Clinical Dementia Rating; SMD, standardized mean difference; SRT, simple reaction time. 


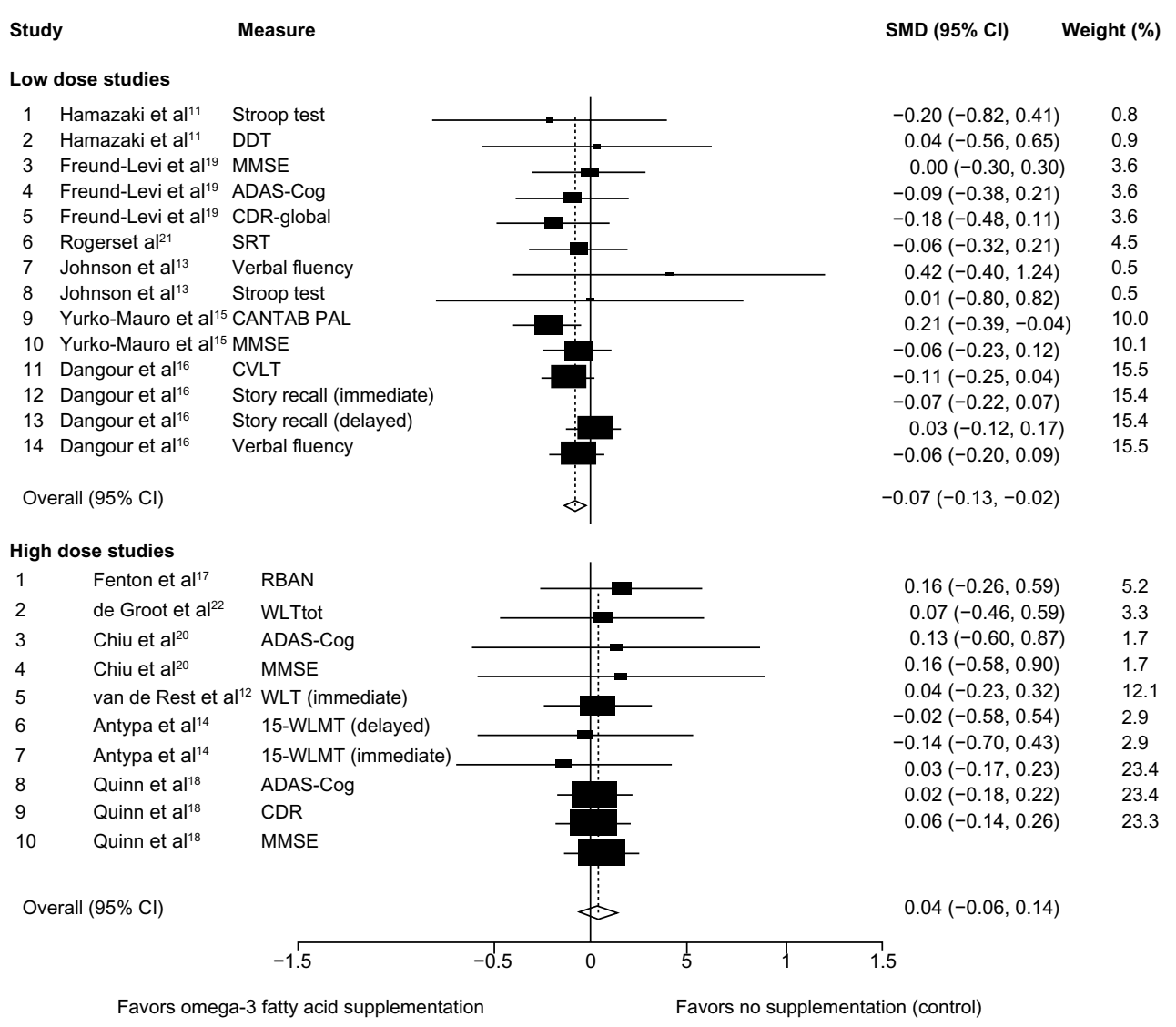

Figure 3 Forest plot of omega-3 fatty acid for low and high dose compared with no supplementation (control).

Abbreviations: ADAS-cog, Alzheimer's Disease Assessment Scale-Cognitive Subscale; CVLT, California Verbal Learning Test; DDT, dementia detecting test; WLTtot, total Words Learning Test; I5-WLMT, Word List (memory) Test; RBANS, Repeatable Battery for the Assessment of Neuropsychological Status; MMSE, Mini-Mental State Examination; WLT, Word Learning Test; PAL, paired associate learning; CDR, Clinical Dementia Rating; SMD, standardized mean difference; SRT, simple reaction time; CI, confidence interval.

dose of supplementation, as shown in Figure 3. Compared with controls, there was a significant reduction in the rate of cognitive decline in groups supplemented with low doses $(\leq 1.73 \mathrm{~g} /$ day) of omega-3 fatty acids (SMD $-0.07,95 \% \mathrm{CI}-0.13,-0.02$ ). There was no evidence of cognitive benefit for supplementation with higher doses of omega-3 fatty acids (SMD +0.04, 95\% CI $-0.06,+0.14)$. Further, no statistically significant heterogeneity was observed in any of the stratified analyses.

\section{Discussion}

There are a number of clinical forms of memory loss, with Alzheimer's disease being the main contributor to the number of patients with dementia. The pathological signs of Alzheimer's disease appears to be susceptible to the effects of DHA, an omega-3 polyunsaturated fatty acid that is essential for the development and maintenance of the prenatal brain and maintenance of vision in adults. ${ }^{23,24}$ Indeed, patients with established Alzheimer's disease have decreased levels of DHA in their brain membrane. ${ }^{25,26}$ Therefore, it is plausible to assume that replenishment of DHA would have a positive impact on memory function. Nonetheless, the clinical trials published thus far have failed to provide a clear consensus on the impact of omega-3 supplementation on cognitive function. The information on the effects of omega-3 on memory function provided in the published literature varies according to the parameter tested, study duration, and the baseline memory function of the subjects participating in the study. These variations ultimately exacerbate ambiguity with regard to the effects of omega-3 supplementation on memory function. Needless to say, memory health/cognition should be considered as the sum of the ability of an individual's memory to respond to various cognitive parameters. Therefore, this study included a pooled analysis on data from 12 relevant published RCTs to determine whether or not omega-3 has any beneficial effects on memory function.

Of the 12 RCTs included in this study, four measured MMSE, three measured ADAS-cog, two measured the Stroop test, four measured various forms of the Word Learning Test, two measured the Clinical Dementia Rating, two measured verbal fluency, one measured Cantab PAL, one measured 
the California Verbal Learning Test, one measured various tasks of simple reaction time, one measured the Repeatable Battery for the Assessment of Neuropsychological Status, and one measured dementia detecting test, giving a total of 24 measurements of different parameters. Where a parameter was reported to be measured in more than one study (eg, MMSE, ADAS-cog, Stroop test, Word Learning Test, or Clinical Dementia Rating) the data were not similar and variation did exist (Figure 2); however, pooling the data indicated a significant positive effect of omega-3 on overall cognitive function, at least for the six low dose studies (see top forest plot of Figure 3). This clearly indicates that clinical trials investigating the impact of an agent on cognition cannot solely rely on testing specific parameters of cognition, but rather a comprehensive assessment of cognition should be included in any clinical trials examining memory function.

The published data examining the impact of omega-3 supplementation has shown contrasting outcomes ${ }^{19,27}$ with no clear explanation. Therefore, in this study, we performed a subanalysis of 12 RCTs for two groups of low-dose (14 parameters assessed) and high-dose (10 parameters assessed) omega-3 usage. Interestingly, clear differences became apparent between the effects of low-dose and highdose omega-3 use on memory function. The subanalysis suggests that low-dose but not higher-dose omega-3 supplementation has positive effects on cognitive function. This variation may in part explain the contrasting reports observed with clinical trials of omega-3 and cognitive function. However, what is important to note is the positive impact of low-dose omega-3 on memory. The mechanism(s) of effect remains to be elucidated, but may include reducing the production of amyloid beta-protein, ${ }^{28,29}$ thus reducing the plaque burden on neuronal cells and ultimately preventing neuronal cell death. This in turn would prevent memory loss and/or reduce the speed of cognitive deterioration.

\section{Acknowledgment}

The authors are grateful to Miss Mahdieh Naderali, University of Leicester, for her editorial assistance in preparing this manuscript.

\section{Disclosure}

The authors report no conflicts of interest in this work.

\section{References}

1. Forsyth E, Ritzline PD. An overview of the etiology, diagnosis, and treatment of Alzheimer disease. Phys Ther. 1998;78(12):1325-1331.

2. Albanese E, Banerjee S, Dhanasiri S, et al. Dementia UK. London, UK: Alzheimer's Society; 2007.
3. Alzheimer's Society. What is dementia? Available from: http://www. alzheimers.org.uk/site/scripts/documents_info.php?documentID=106. Accessed July 5, 2014.

4. Evin G, Weidemann A. Biogenesis and metabolism of Alzheimer's disease Abeta amyloid peptides. Peptides. 2002;23(7):1285-1297.

5. Barghorn S, Nimmrich V, Striebinger A, et al. Globular amyloid beta-peptide oligomer - a homogenous and stable neuropathological protein in Alzheimer's disease. $J$ Neurochem. 2005;95(3): 834-847.

6. Lacor PN, Buniel MC, Furlow PW, et al. Abeta oligomer-induced aberrations in synapse composition, shape, and density provide a molecular basis for loss of connectivity in Alzheimer's disease. J Neurosci. 2007;27(4):796-807.

7. Weih W, Wiltfang J, Kornhuber J. Non-pharmacologic prevention of Alzheimer's disease: nutritional and life-style risk factors. $J$ Neural Transm. 2007;114(9):1187-1197.

8. Naderali EK, Ratcliffe SH, Dale MC. Obesity and Alzheimer's disease: a link between body weight and cognitive function in old age. $\mathrm{Am} J$ Alzheimers Dis Other Demen. 2009;24(6):445-449.

9. Gustaw-Rothenberg K. Dietary patterns associated with Alzheimer's disease: population based study. Int J Environ Res Public Health. 2009;6(4):1335-1340.

10. Scarmeas N, Stern Y, Mayeux R, Manly JJ, Schupf N, Luchsinger JA. Mediterranean diet and mild cognitive impairment. Arch Neurol. 2009;66(2):216-225.

11. Hamazaki T, Sawazaki S, Itomura M, et al. The effect of docosahexaenoic acid on aggression in young adults: a placebo-controlled double-blind study. J Clin Invest. 1996;97(4):1129-1133.

12. van de Rest O, Geleijnse JM, Kok FJ, et al. Effect of fish oil on cognitive performance in older subjects: a randomized, controlled trial. Neurology. 2008;71(6):430-438.

13. Johnson EJ, McDonald K, Caldarella SM, Chung HY, Troen AM, Snodderly DM. Cognitive findings of an exploratory trial of docosahexaenoic acid and lutein supplementation in older women. Nutr Neurosci. 2008;11(2):75-83.

14. Antypa N, Van der Does AJW, Smelt AHM, Rogers RD. Omega-3 fatty acids (fish-oil) and depression-related cognition in healthy volunteers. J Psychopharmacol. 2009;23(7):831-840.

15. Yurko-Mauro K, McCarthy D, Rom D, et al; MIDAS Investigators. Beneficial effects of docosahexaenoic acid on cognition in age-related cognitive decline. Alzheimers Dement. 2010;6(6):456-464.

16. Dangour AD, Allen E, Elbourne D, et al. Effect of 2-y n-3 long-chain polyunsaturated fatty acid supplementation on cognitive function in older people: a randomized, double-blind, controlled trial. Am J Clin Nutr. 2010;91(6):1725-1732.

17. Fenton WS, Dickerson F, Boronow J, Hibbeln JR, Knable M. A placebo-controlled trial of omega-3 fatty acid (ethyl eicosapentaenoic acid) supplementation for residual symptoms and cognitive impairment in schizophreni(a). Am J Psychiatry. 2001;158(12):2071-2074.

18. Quinn JF, Raman R, Thomas RG, et al. Docosahexaenoic acid supplementation and cognitive decline in Alzheimer disease: a randomized trial. JAMA. 2010;304(17):1903-1911.

19. Freund-Levi Y, Eriksdotter-Jönhagen M, Cederholm T, et al. Omega-3 fatty acid treatment in 174 patients with mild to moderate Alzheimer disease: OmegAD study: a randomized double-blind trial. Arch Neurol. 2006;63(10):1402-1408.

20. Chiu CC, Su KP, Cheng TC, et al. The effects of omega-3 fatty acids monotherapy in Alzheimer's disease and mild cognitive impairment: a preliminary randomized double-blind placebo-controlled study. Prog Neuropsychopharmacol Biol Psychiatry. 2008;32(6):1538-1544.

21. Rogers PJ, Appleton KM, Kessler D, et al. No effect of n-3 longchain polyunsaturated fatty acid (EPA and DHA) supplementation on depressed mood and cognitive function: a randomised controlled trial. Br J Nutr. 2008;99(2):421-431.

22. de Groot RH, Adam J, Jolles J, Hornstra. Alpha-linolenic acid supplementation during human pregnancy does not affect cognitive functioning. Prostaglandins Leukot Essent Fatty Acids. 2004;70(1):41-47. 
23. Calon F, Cole G. Neuroprotective action of omega-3 polyunsaturated fatty acids against neurodegenerative diseases: evidence from animal studies. Prostaglandins Leukot Essent Fatty Acids. 2007;77(5-6): 287-293.

24. Mitchell DC, Gawrisch K, Litman BJ, Salem N Jr. Why is docosahexaenoic acid essential for nervous system function? Biochem Soc Trans. 1998;26(3):365-370.

25. Prasad MR, Lovell MA, Yatin M, Dhillon H, Markesbery WR. Regional membrane phospholipid alterations in Alzheimer's disease. Neurochem Res. 1998;23(1):81-88.

26. Soderberg M, Edlund C, Kristensson K, Dallner G. Fatty acid composition of brain phospholipids in aging and in Alzheimer's disease. Lipids. 1991;26(6):421-425.
27. Devore EE, Grodstein F, van Rooij FJ, et al. Dietary intake of fish and omega-3 fatty acids in relation to long-term dementia risk. Am J Clin Nutr. 2009;90(1):170-176.

28. Lim GP, Calon F, Morihara T, et al. A diet enriched with the omega-3 fatty acid docosahexaenoic acid reduces amyloid burden in an aged Alzheimer mouse model. J Neurosci. 2005;25(12):3032-3040.

29. Mucke L, Masliah E, Yu GQ, et al. High-level neuronal expression of Abeta 1-42 in wild-type human amyloid protein precursor transgenic mice: synaptotoxicity without plaque formation. JNeurosci. 2000;20(11):4050-4058.
International Journal of General Medicine

\section{Publish your work in this journal}

The International Journal of General Medicine is an international, peer-reviewed open-access journal that focuses on general and internal medicine, pathogenesis, epidemiology, diagnosis, monitoring and treatment protocols. The journal is characterized by the rapid reporting of reviews, original research and clinical studies across all disease areas.

\section{Dovepress}

A key focus is the elucidation of disease processes and management protocols resulting in improved outcomes for the patient.The manuscript management system is completely online and includes a very quick and fair peer-review system. Visit http://www.dovepress.com/ testimonials.php to read real quotes from published authors.

Submit your manuscript here: http://www.dovepress.com/international-journal-of-general-medicine-journal 